Another important task for the future is to try to find methods for early diagnosis of osteoarthritis to create a basis for earlier intervention and treatment. This will include further evaluation of new diagnostic techniques, both in selected patient groups and in the general population. Such studies might in the future give us "new" and more clinically relevant prevalence figures. The question of secular trends also remains to be solved.

Much knowledge has already been gained but much more work needs to be done.

1 Lawrence JS. Generalized osteoarthritis in a population sample. Am f Epidemiol 1969;90:381-9.

2 Lawrence JS, Bremner JM, Bier F. Osteo-arthrosis. Prevalence in the population and relationship between symptoms and x-ray changes. Ann Rheum Dis 1966;25:1-24.

3 Kellgren JH, Lawrence JS. Osteo-arthrosis and disk degeneration in an urban population. Ann Rheum Dis 1958; 17:388-97.

4 Lim KKT, Rogers J, Sheepstone L, Dieppe PA. The evolutionary origins of osteoarthritis: a comparative skeletal study of hand disease in 2 primates. 7 Rheumatol 1995;22:2132-4.

5 Rogers J, Watt I, Dieppe P. Arthritis in Saxon and medieval skeletons. BMF 1981;283:1668-70.

6 Jurmain RD, Kilgore L. Skeletal evidence of osteoarthritis: a paleopathological perspective. Ann Rheum Dis 1995; 54:443-50.

7 Rogers J, Dieppe PA. Is tibiofemoral osteoarthritis in the knee joint a new disease? Ann Rheum Dis 1994;53:612-3.

8 Spector TD, Hart DJ, Byrne J, Harris PA, Dacre JE, Doyle DV. Definition of osteoarthritis of the knee for epidemiological studies. Ann Rheum Dis 1993;52:790-4.

9 Spector TD, Hochberg MC. Methodological problems in the epidemiological study of osteoarthritis. Ann Rheum Dis 1994;53:143-6.

10 Kellgren JH, Jeffrey M, Ball J. Atlas of standard radiographs. The epidemiology of chronic rheumatism, vol 2 . Oxford: The epidemiology

11 Bagge E, Edén S, Bjelle A, Svanborg A. Osteoarthritis in the elderly. Clinical and radiographic findings in 79 and 85-years-old. Ann Rheum Dis 1991;50:535-9.

12 Kellgren JH. Osteoarthrosis in patients and populations. BMF 1961;ii: 1-6.

13 Bagge E, Bjelle A, Svanborg. Radiographic osteoarthritis in the elderly. A cohort comparison and a longitudinal study of the "70-year old people in Göteborg". Clin Rheumatol 1992:11:486-91.

14 Jacobsson L, Lindgärde F, Manthorpe R. The commonest rheumatic complaints of over six weeks duration during a rheumatic complaints of over six weeks duration during a 12-month period in a defined Swedish population: preva-
15 Spector T, Hart D. How serious is knee osteoarthritis? Ann Rheum Dis 1992;51:1105-6.

16 Lequesne M, Altman R. Osteoarthritis of the hand. New methods. New data. Rev Rhum 1995;62(suppl 1):1-2S.

17 Kallman DA, Wigley FM, Scott WWJ, Hochberg MC, Tobin JD. New radiographic grading scales for osteoarthritis of the hand: reliability for determining prevalence and progression. Arthritis Rheum 1989;32:1584-91.

18 Hart DJ, Spector TD, Egger P, Coggon D, Cooper C. Defining osteoarthritis of the hand for epidemiologic studies. The Chingford sudy. Ann Rheum Dis 1994;53:220-3.

19 Cicuttini FM, Spector TD. The epidemiology of osteoarthritis of the hand. Rev Rhum 1995;62(suppl1):3-8S

20 Bagge E, Bjelle A, Valkenburg H, Svanborg A. Prevalence of radiographic osteoarthritis in two elderly European populations. Rheumatol Int 1992;12:33-8.

21 Jørring K. Osteoarthritis of the hip. Epidemiology and clinical role. Acta Orthop Scand 1980;51:523-30.

22 Danielsson LG. Incidence of osteoarthrits of the hip. Clin Orthop 1966;45:67-72.

23 Lindberg H. Epidemiological studies on primary coxarthrosis. Malmö: University of Lund, 1985.

24 van Saase JLCM, van Romunde LKJ, Cats A, Vandenbroucke JP, Valkenburg HA. Epidemiology of osteoarthritis: Zoetermer survey. Comparison of radiological osteoarthritis in a Dutch population with that in 10 other populations. Ann Rheum Dis 1989;48:271-80.

25 Lawrence RC, Hochberg MC, Kelsey JL, McDuffie FC, Medsger TA, Felts WR, et al. Estimates of the prevalence of selected arthritic and muskuloskeletal diseases in the United States. F Rheumatol 1989;16:427-41.

26 Ahlbäck S. Osteoarthrosis of the knee: a radiographic investigation. Acta Radiol (Stockholm) 1968;suppl 277:7-

27 McAlindon TE, Snow S, Cooper C, Dieppe PA. Radiographic patterns of osteoarthritis of the knee joint in the community;the importance of the patellofemoral joint. Ann Rheum Dis 1992;51:844-9.

28 Spector TD, Hart DJ, Leedham-Green M. The prevalence of knee and hand osteoarthritis (OA) in the general population using different clinical criteria: the Chingford study. Arthritis Rheum 1991;34:S171.

29 Oliveria SA, Felson DT, Reed JI, Cirillo PA, Walker AM. Incidence of symptomatic hand, hip, and knee osteoarthritis among patients in a health maintenance organization. Arthritis Rheum 1995;38:1134-41.

30 Felson DT, Zhang Y, Hannan MT, Naimark A, Weissman BN, Aliabadi $\mathrm{P}$, et al. The incidence and natural history of knee osteoarthritis in the elderly. Arthritis Rheum 1995; 38:1500-5.

31 Schouten JSAG. A twelve year follow-up study on osteoarthritis of the knee in the general population. Rotterdam: Erasmus University, 1990.

32 Spector TD, Hart DJ, Doyle DV. Incidence and progression of osteoarthritis in women with unilateral knee disease in the general population: the effect of obesity. Ann Rheum Dis 1994;53:565-8.

\title{
The occurrence of osteoarthritis outside Europe
}

\author{
Peter Croft
}

A traditional epidemiological tool is to describe the distribution of a disease by personal characteristics (such as age or gender), time, and place. The argument for looking at geographical variation is that if people living in different places have different rates of disease, then it is possible to define what it is about the places which might protect against or cause the condition. In this paper I consider some of the evidence about the occurrence of osteoarthritis outside European and Caucasian populations and highlight some questions raised by this evidence. Although all osteoarthritis can be lumped together for some purposes, it is more useful to consider disease of each joint group as a separate entity. This paper will focus initially on the geographical variation of osteoarthritis in one joint in particular (the hip), but will turn

\footnotetext{
to disease in other joints also.
}

Prevalence studies around the world have used four methods of case ascertainment: (1) radiographic surveys of the general population; (2) radiographic surveys of hospital attenders; (3) surveys of osteoarthritis patients admitted to hospital; (4) necropsy studies.

\section{General population studies}

General population surveys have to start with ancestor worship. The extraordinary studies of Kellgren and Lawrence and their international collaborators in the $1950 \mathrm{~s}$ tackled issues of observer repeatability and the need for standardised methods of disease definition in international comparisons of musculoskeletal disease long in advance of most other clinical disciplines. ${ }^{1}$

Their basic findings still stand: (1) osteoarthritis occurs everywhere, and (2) oste-
Drive, Hartshill,

Stoke-on-Trent ST 4 7QB, United Kingdom P Croft
School of Postgraduate Medicine, Industrial and Community Health Research 
oarthritis prevalence is generally higher in Europe and America than elsewhere in the world.

Because of the lower overall prevalence of hip osteoarthritis compared with other joints, the older age group involved, and the ethical difficulties of random pelvic radiography, hips were often excluded from Lawrence's international comparisons. There were exceptions, notably the survey of a rural district of Jamaica. ${ }^{2}$ The prevalence of radiographic hip osteoarthritis was lower in this community than in a rural community in Britain. Numbers were small, but the two studies in Jamaica and Britain had involved the same methods and the same observers.

Most evidence about international variations in hip osteoarthritis occurrence have come from hospital based studies.

\section{Case series}

Incidence rates derived from patients who attend hospital because of hip osteoarthritis are much lower in countries such as Nigeria or India than in Europe and America. ${ }^{34}$ However, this may simply reflect differences in the availability of care, access to care, and demand for care rather than differences in the prevalence of the disease.

Hoaglund and colleagues compared the rates of total hip replacement in different ethnic groups in the catchment area of San Francisco. ${ }^{5}$ The results showed an age standardised incidence of hip replacement for primary hip osteoarthritis in whites (75.5 per 100 000) which was 10 times higher than that in the Chinese population, with blacks intermediate, and other groups closer to the Chinese rates. Different levels of ascertainment of total hip replacements in the different groups were unlikely to be a bias and certainly could not explain such large differences. How much of the variation might be explained by different propensities to seek care or by variable access to health services in the different groups? Not much, according to the researchers, basing their argument on the finding that given a specific diagnosis such as avascular necrosis, which was more common in blacks than whites, the likelihood of a total hip replacement was similar in the two groups. However, variable health care utilisation by different ethnic groups is a well recorded phenomenon in America and it is likely that it had some influence here.

\section{Hospital populations}

There have been attempts to get around the problem of the selectivity of patients who seek health care for their osteoarthritis-notably by surveying samples of hospital patients regardless of their presenting problem. Hoaglund et al obtained additional study $x$ rays from a range of Hong Kong Chinese patients attending hospital. ${ }^{6}$ This confirmed a lower prevalence of radiographic hip osteoarthritis in this population when compared to figures from a population radiographic survey carried out by Kellgren and Lawrence in an urban setting in Britain. However, there were different observers in the two studies and the populations were selected in different ways. Some 25 years later, Lau and colleagues in Hong Kong carried out a survey in Chinese men aged 60-75 years who had presented as outpatients for intravenous urography. ${ }^{7}$ Although these men were not selected because they were seeking care for hip pain, they still might not have been representative of the older Hong Kong male population. To address this, the results were compared with British men aged 60-75 years who had been sampled in the same way from outpatients attending hospital. In addition one observer was common to both studies. Hip osteoarthritis prevalence was lower in the Hong Kong Chinese men. A parallel study by Abu Ali-Gombe et al in Nigeria, using similar methods, suggested a similarly low prevalence in older Nigerian men. ${ }^{8}$

\section{Bias in the studies}

For patients and clinicians, pain, stiffness, and disability are important defining features of osteoarthritis. If we were studying symptomatic osteoarthritis or health service utilisation for osteoarthritis, our interpretation of international comparisons would be different. However, the comparisons are concerned with what causes osteoarthritis to arise in the first place, and radiographic change has been taken as the gold standard of diagnosis to address this question.

Health care utilisation seems to be ruled out as the sole explanation for variations in hip osteoarthritis prevalence, given the numbers of studies which have specifically sought to avoid selection bias. Pain complaints and disability may vary cross-culturally for a given level of radiographic change, but this does not explain the variations either. Statistical power is often not high but the consistency of the findings is an impressive argument against differences in prevalence arising wholly from chance, particularly given the range of methods used.

\section{Interpretation of the studies}

Why might hip osteoarthritis prevalence be lower in countries outside Europe and America and between ethnic groups within those continents?

GENERALISED TENDENCY TO OSTEOARTHRITIS

Osteoarthritis in any joint is likely to be a result of interplay between a generalised propensity to osteoarthritis and local factors acting at a specific joint. This means that we do not know how much of osteoarthritis is nature, how much nurture. In particular we lack good international comparisons of the heritability of osteoarthritis. However, we can get a clue from the distribution of Heberden's nodes between countries, if we assume nodes to be a marker for generalised osteoarthritis. The Kellgren and Lawrence studies suggested that Heberden's nodes are much less frequent in African and Caribbean populations than in the British samples. ${ }^{129}$ Hoaglund reported a high prevalence in the Hong Kong Chinese, but observer variation and selection differences might have accounted for this. ${ }^{6}$ 
Polyarticular osteoarthritis is also less frequent in countries outside Europe and America, although the prevalence of osteoarthritis in three or more joints was similar in the Jamaican and Wensleydale studies. ${ }^{2}$ However, this might reflect differences in age related occurrence or risk factor prevalence for each joint site separately and cannot be interpreted as meaning a lower general tendency towards osteoarthritis.

More light is shed from necropsy studies. British and Indian researchers have compared osteoarthritic changes in cadaveric hips in small but reasonably unselected samples. ${ }^{10}$ They identified articular changes which are universal at older ages in Caucasian hips and which do not inevitably progress; comparable changes were found in necropsied hips from India and Hong Kong. Progressive changes typical of established osteoarthritis were much less frequent overall, but were more likely to be found in the Caucasian hips. This parallels the recent Hong Kong and Nigerian data, ${ }^{78}$ in which the prevalence of isolated joint space narrowing or of an isolated osteophyte was remarkably similar to that in the British comparator population. This raises the possibility that the ubiquitous nature of osteoarthritis reflects universal age related changes which under certain environmental circumstances or genetic propensities, varying in extent between populations, can progress to osteoarthritic disease.

\section{UNDERLYING DISEASE}

The San Francisco studies of Hoaglund suggested that primary hip osteoarthritis (that is, the absence of underlying hip disease) constituted the main difference in arthroplasty rates between ethnic groups. ${ }^{5}$ Certain specific causes appeared to be as common in other groups as in whites, but it may be that international variations in osteoarthritis prevalence reflect different patterns of underlying hip problems. Developmental abnormalities of the hip are a major candidate, and the geography of congenital hip dislocation does mirror the geography of hip osteoarthritis (figure). The problem is that the excess prevalence of hip osteoarthritis in Europe and the USA cannot be explained by the known incidence of developmental diseases. Minor structural abnormalities which do not present in childhood could have a much greater influence.

The hypothesis would be that acetabular dysplasia, for example, is more common in Europe and America than in countries where hip prevalence is low. Evidence from Hong Kong and Nigeria is against this idea. $^{78}$ Acetabular depths were actually shallower in these populations compared with a comparable group in Britain. When hip osteoarthritis does occur in these populations, it is proportionately more likely to be secondary to acetabular dysplasia. ${ }^{611}$ The lower prevalence of hip osteoarthritis in these countries is thus not explained by a lower prevalence of hip dysplasia but by the relative rarity of "primary" hip osteoarthritis.

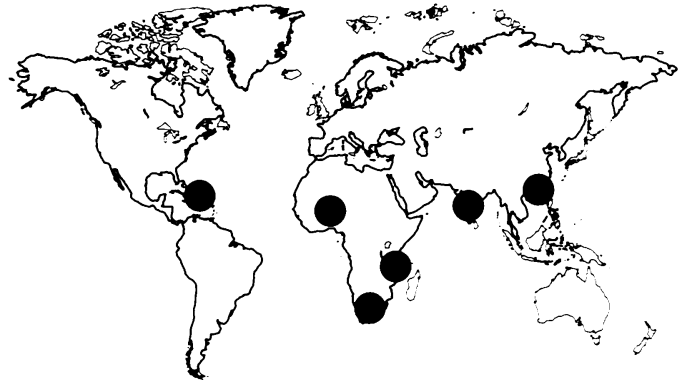

Areas where congenital dislocation and osteoarthritis of the hip are rare.

RISK FACTORS

Other contributors to this symposium will be considering the known risk factors for hip osteoarthritis. International variations in prevalence can do little but raise the possibility that lifestyle and environment may be important influences. However, one small deduction can be made from the Nigerian and Jamaican studies. The biggest risk group for hip osteoarthritis in Europe has been farmers, with physical activity the suggested culprit. The Jamaican and Nigerian study populations were also farming communities: why is their prevalence lower than that of the general population in Europe and America? If they were to be compared with similarly aged farmers in Europe, the contrasts in prevalence would be far greater.

\section{PROTECTION FACTORS}

Lastly there is the possibility that aspects of life in countries outside Europe and America might protect against hip osteoarthritis. One suggestion is that squatting, with the hip contained comfortably under even pressure in the acetabulum, protects and nurtures mechanical resistance to deformity of the hip. But what is good for the hip is in biomechanical terms potentially harmful to the knee. In a workshop full of experts on the knee, the final thought comes from a consideration of variations in prevalence of osteoarthritis in that joint. If the cultural biomechanics of posture and activity hold the clue as to why osteoarthritis varies around the world, then knee osteoarthritis should not be such a rare phenomenon, assuming potential stresses on the knee to be universal. The Jamaican data show clearly that radiographic knee osteoarthritis was commoner there than in the rural comparison community of Wensleydale. The studies of Adebajo in Nigeria suggest that knee osteoarthritis is not an unusual reason for hospital attendance in that country. ${ }^{12}$ From the COPCORD studies ${ }^{13}$ and from comparisons of blacks and Caucasians in American population samples, ${ }^{14}$ the message is that knee and hip are different, and that knee osteoarthritis may be as common outside Europe as within. However, the studies do have flaws and stronger international comparison studies are needed. A personal summary of important areas for future research would thus include:

(1) The ratio of knee to hip prevalence in different countries.

(2) Geographical variations in polyarticular osteoarthritis in different age groups. 
(3) Studies comparing prevalence in similar risk groups sampled from different countries.

This work reflects a close collaboration with Cyrus Cooper and David Cogson of the MRC Environmental Epidemiology Unit and Alan Silman of the ARC Epidemiology Research Unit, as well as our good friends abroad.

1 Lawrence JS, Sebo M. The geography of osteoarthrosis. In: Nuki G, ed. The aetiopathogenesis of osteoarthrosis. Tunbridge Wells: Pitman Medical, 1980:155-83.

2 Lawrence JS, Molyneux M. Degenerative joint disease among populations in Wensleydale, England and Jamaica. among populations in Wiometeorol 1968;12:163-75.

3 Ebong WW, Lawson EAL. Pattern of osteoarthritis of the hip in Nigerians. East Af Med $¥$ 1978;55:81-4.

4 Mukhopadya B, Barooah B. Osteoarthritis of the hip in Indians : an anatomical and clinical study. Indian $\mathcal{F}$ Orthop 1967;1:55-62.

5 Hoaglund FT, Oishi CS, Gialamas GG. Extreme variations in racial rates of total hip arthroplasty for primary coxarthrosis: a population-based study in San Francisco. Ann Rheum Dis 1995;54:107-10.
6 Hoaglund FT, Yau ACMC, Wong WL Osteoarthritis of the hip and other joints in Southern Chinese in Hong Kong. $f$ Bone foint Surg Am 1973;55A:545-57.

7 Lau EMC, Lin F, Lam D, Silman A, Croft P. Hip osteoarthritis and dysplasia in Chinese men. Ann Rheum Dis 1995;54:965-9.

8 Ali-Gombe A, Croft PR, Silman AJ. Osteoarthritis of the hip and acetabular dysplasia in Nigerian men. $₹$ Rheumatol and acetabular dysp

9 Solomon L, Beighton P, Lawrence JS. Osteoarthritis in a rural South African Negro population. Ann Rheum Dis 1976;35:274-9.

10 Byers PD, Hoaglund FT, Purewal GS, Yau ACMC. Articular cartilage changes in Caucasian and Asian hip joints. Ann Rheum Dis 1974;33:157-61.

11 Hoaglund FT, Shiba R, Newberg AH, et al. Diseases of the hip. $\mathcal{F}$ Bone foint Surg Am 1985;67A:1376-83.

12 Adebajo AO. Epidemiology and community studies: Africa. Baillieres Clin Rheumatol 1995;9:21-30.

13 Muirden KD. Epidemiology and community studies: Asia/Pacific region. Baillieres Clin Rheumatol 1995;9:1120.

14 Felson DT. Epidemiology of hip and knee osteoarthritis. Epidemiol Rev 1968;10:1-28. 